Article

\title{
Regulation of Inflammatory Cytokines in \\ Lipopolysaccharide-Stimulated RAW 264.7 \\ Murine Macrophage by 7-O-Methyl-naringenin
}

\section{Lanan Wassy Soromou ${ }^{1, \dagger}$, Zhichao Zhang ${ }^{2, \dagger}$, Rongtao $\mathrm{Li}^{3, \dagger}{ }^{3,}$ Na Chen ${ }^{1}$, Weixiao Guo ${ }^{1}$,} Meixia Huo ${ }^{1}$, Shuang Guan ${ }^{1,4, *}$, Jing Lu ${ }^{1,4, *}$ and Xuming Deng ${ }^{1, *}$

1 College of Animal Science and Veterinary Medicine, Jilin University, Changchun 130062, Jilin, China

2 ChangChun Central Hospital, Changchun 130051, Jilin, China

3 College of Life Science and Technology, Kunming University of Science and Technology, Kunming 650224, China

4 Laboratory of Nutrition and Function Food, Jilin University, Changchun 130062, Jilin, China

$\dagger$ These authors contributed equally to this work.

* Authors to whom correspondence should be addressed; E-Mails: gshuang1973@126.com (S.G.); xlujing1@yahoo.com.cn (J.L.); xumingdeng@yahoo.com.cn (X.D.); Tel.: +86-431-8783-6161; Fax: +86-431-8783-6160.

Received: 4 January 2012; in revised form: 27 February 2012 / Accepted: 15 March 2012 / Published: 22 March 2012

\begin{abstract}
O-Methylnaringenin, extracted from Rhododendron speciferum, belongs to the flavanone class of polyphenols. In the present study, we investigated the anti-inflammatory effects of 7-O-methylnaringenin on cytokine production by lipopolysaccharide (LPS)-stimulated RAW 264.7 macrophages in vitro. The results showed that pretreatment with 10,20 or $40 \mu \mathrm{g} / \mathrm{mL}$ of $7-O$-methylnaringenin could downregulate tumour necrosis factor (TNF- $\alpha$ ), interleukin (IL-6) and interleukin (IL-1 $\beta$ ) in a dose-dependent manner. Furthermore, we investigated the signal transduction mechanisms to determine how 7-O-methylnaringenin affects RAW 264.7 macrophages. The activation of mitogen-activated protein kinases (MAPK) and $\mathrm{I} \kappa \mathrm{B} \alpha$ were measured by Western blotting. The data showed that 7-O-methylnaringenin could downregulate LPS-induced levels of phosphorylation of ERK1/2, JNK and $\mathrm{I} \kappa \mathrm{B} \alpha$. These observations indicated that 7-O-methylnaringenin modulated inflammatory cytokine responses by blocking NF-қ $\mathrm{B}$, ERK1/2 and JNK/MAPKs activation.
\end{abstract}


Keywords: 7-O-methylnaringenin; anti-inflammation; signal pathways; cytokines

\section{Introduction}

Inflammation is a rapid response of tissue to injury and characterized in the acute phase by increased blood flow and vascular permeability along with the accumulation of fluid, leucocytes, and inflammatory mediators, such as cytokines [1]. LPS is a major constituent of the outer membrane of Gram-negative bacteria. It can activate mononuclear phagocytes (monocytes and macrophages) and other types of cells to secrete TNF- $\alpha$, IL- 6 , IL-1 $1 \beta$. The excessive production of these cytokines may result in the systemic inflammatory response syndrome (SIRS), severe tissue damage, and septic shock [2,3]. Among the cytokines, TNF- $\alpha$ is thought to be one of the most important mediators of inflammatory diseases. It is elevated in some pathogenic conditions and possesses potential toxic effect that results in hypersensitivity reactions with chronic inflammation [4,5]. IL-6 is a cytokine produced by a number of normal and transformed cells. It is believed to be an endogenous mediator of LPS-induced fever [6-8]. IL-1 is a multifunctional cytokine that is responsible for various processes including host defense, inflammation and response to injury. It is produced by many cell types, predominantly by macrophages $[9,10]$. In recent years, people began to use extracts from natural medicinal plants to prevent and treat inflammatory responses by inhibiting inflammatory cytokines, such as TNF- $\alpha$, IL-1 $\beta$ and IL-6, and this has become an important area of investigation.

Flavones are a group of natural compounds widely generated by plants [11]. Previous studies proved that they have various biological activities, such as anti-oxidant [12], anti-inflammatory [13], anti-allergic [14], anti-infectious [15], anti-carcinogenic [16], pro-apoptotic [17,18] and anti-hypertensive [19] properties. 7-O-Methylnaringenin (Figure 1), isolated from Rhododendron speciferum for the first time, belongs to the flavanone class of polyphenols [20].

Figure 1. Chemical structure of 7-O-methylnaringenin.<smiles>COc1cc(O)cc2c1C(=O)CC(c1ccc(O)cc1)O2</smiles>

Ahmed et al. have reported that 7-O-methylnaringenin possesses antimalarial activity with a MIC value of approximately $100 \mu \mathrm{g} / \mathrm{mL}$ [21], but there is no description of the anti-inflammatory effects of 7-O-methylnaringenin. Thus, the aim of the present study was to investigate the anti-inflammatory effects of 7-O-methylnaringenin on LPS-activated pro-inflammatory cytokines production in RAW 264.7 macrophages. Additionally, to determine the mechanism(s) underlying the anti-inflammatory effects of 7-O-methylnaringenin, we studied whether this flavone has any influence on the MAPK and $\mathrm{NF}-\kappa \mathrm{B}$ activation. Our results show that 7-O-methylnaringenin significantly inhibits production of pro-inflammatory cytokines induced by LPS in vitro by blocking the LPS-induced NF-қB, ERK1/2 and JNK/MAPKs signalling pathways. 


\section{Results and Discussion}

\subsection{Effect of 7-O-Methylnaringenin on Macrophage Toxicity}

RAW 264.7 cells were incubated with 7-O-methylnaringenin in amounts ranging from 0 to $50 \mu \mathrm{g} / \mathrm{mL}$ and cell viability was measured by an MTT assay $18 \mathrm{~h}$ later. We found that $7-O$-methylnaringenin from 0 to $50 \mu \mathrm{g} / \mathrm{mL}$ had no cytotoxic effects on RAW 264.7 cells (Figure 2). These results confirmed that the effects of 7-O-methylnaringenin on RAW 264.7 cells were not due to a reduction in cell viability.

Figure 2. Effects of 7-O-methylnaringenin on the viability of RAW 264.7 cells. RAW 264.7 cells were incubated in the presence or absence of 7-O-methylnaringenin ( 0 to $50 \mu \mathrm{g} / \mathrm{mL}$ ) for $24 \mathrm{~h}$. Cell viability was determined by the MTT assay. Data are presented as means \pm SEM of three independent experiments.

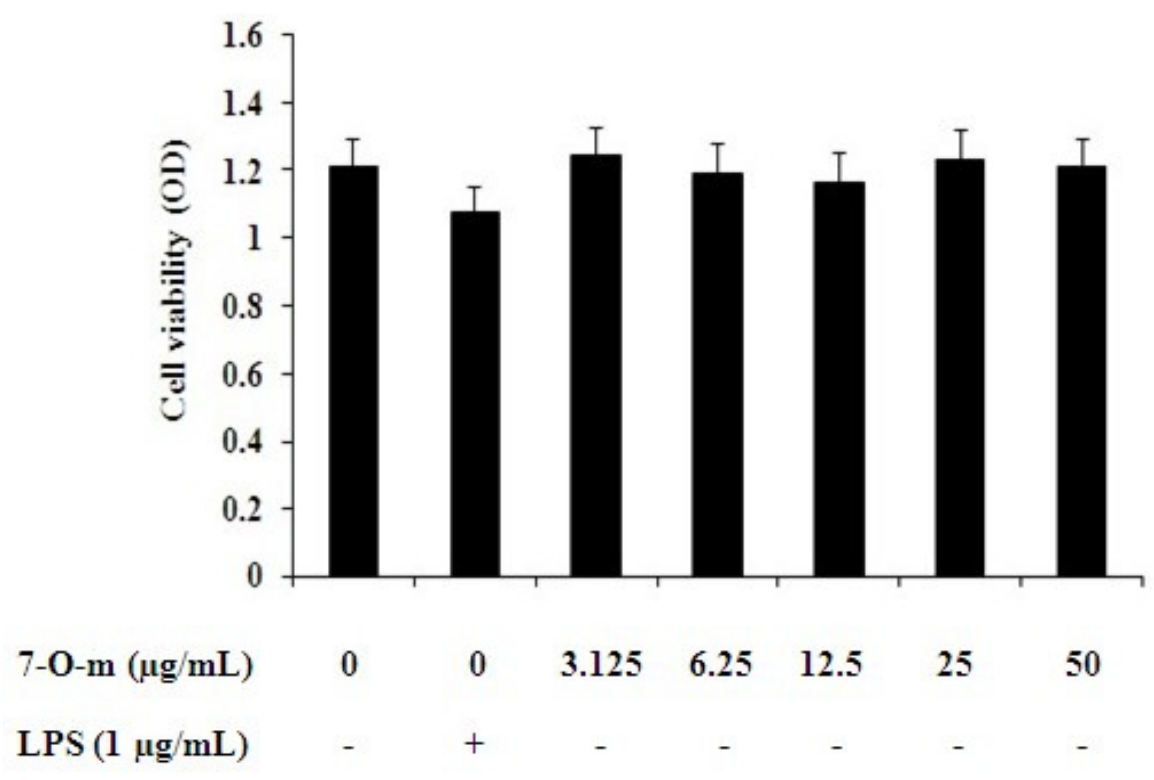

\subsection{Effects of 7-O-Methylnaringenin on LPS-Induced Cytokine Production}

The concentrations of TNF- $\alpha$, IL- 6 and IL-1 $\beta$ in the culture supernatants of RAW 264.7 cells were measured by an ELISA kit (Figure 3). Treatment of RAW 264.7 cells with LPS alone resulted in significant increases in cytokine production as compared to the control group. The levels of TNF- $\alpha$, IL-6 and IL-1 $\beta$ were significantly decreased as compared to the LPS group in a dose-dependent manner in $7-O$-methylnaringenin groups $(* * p<0.01)$.

\subsection{The Effects of 7-O-Methylnaringenin on LPS-Induced MAPK Pathways Activation}

In order to investigate the mechanism by which 7-O-methylnaringenin inhibits LPS-induced production of inflammatory cytokines, we examined the effect of 7 - $O$-methylnaringenin on the LPS-induced phosphorylation of ERK1/2, JNK and p38 MAPK in the cytoplasm by Western blotting analysis using three different phospho-specific antibodies. As shown in Figure 4, the phosphorylation level of the ERK1/2, JNK and p38 MAPK increased dramatically after 30 min of stimulation with 
LPS. 7- $O$-methylnaringenin markedly inhibited LPS-induced activation of p-ERK1/2, p-JNK/MAPKs in a dose-dependent manner. But there were no significant changes in p-p38/MAPKs.

Figure 3. Effect of different concentrations of 7-O-methylnaringenin on the secretion of TNF- $\alpha$ (a), IL-6 (b) and IL-1 $\beta$ (c) in LPS-stimulated RAW 264.7 cells. The cells were pretreated with different concentrations $(5,10,20$ and $40 \mu \mathrm{g} / \mathrm{mL})$ of $7-O$-methylnaringenin for $1 \mathrm{~h}$ prior to stimulation with $1 \mu \mathrm{g} / \mathrm{mL}$ of LPS for $24 \mathrm{~h}$. Control values were obtained in the absence of LPS or 7-O-methylnaringenin. The values are means \pm SEM of three independent experiments. ${ }^{*} p<0.05, * * P<0.01 v s$. LPS group.

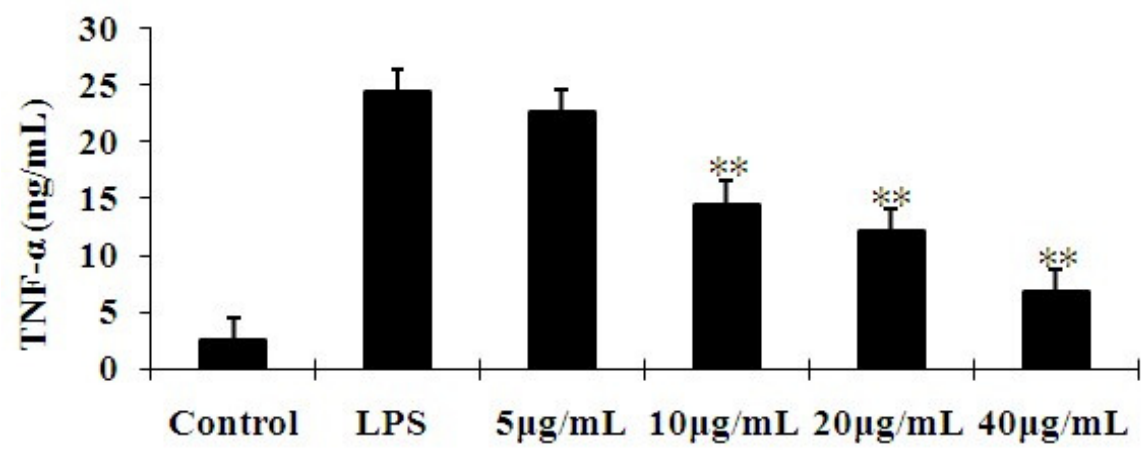

Concentration

(a)

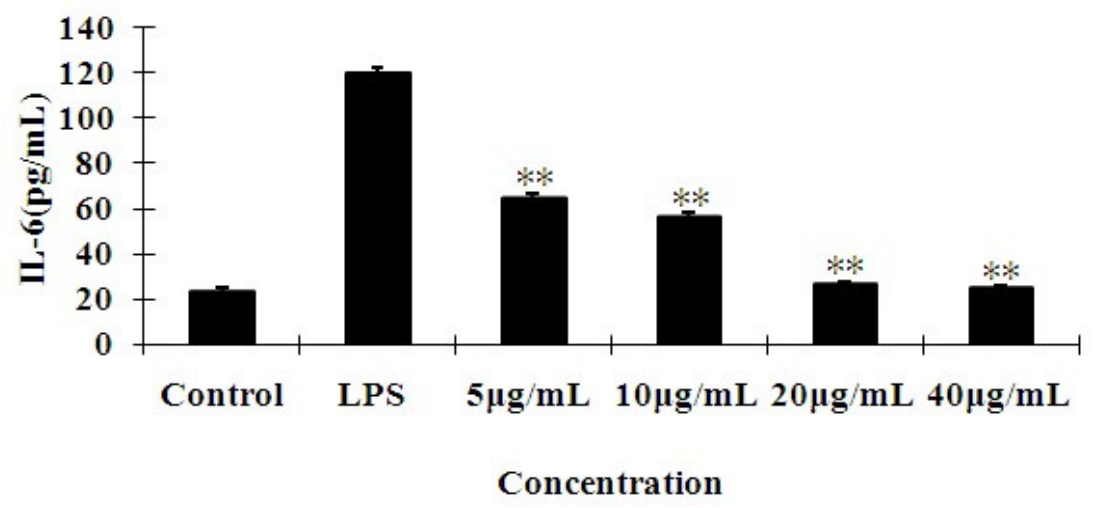

(b)

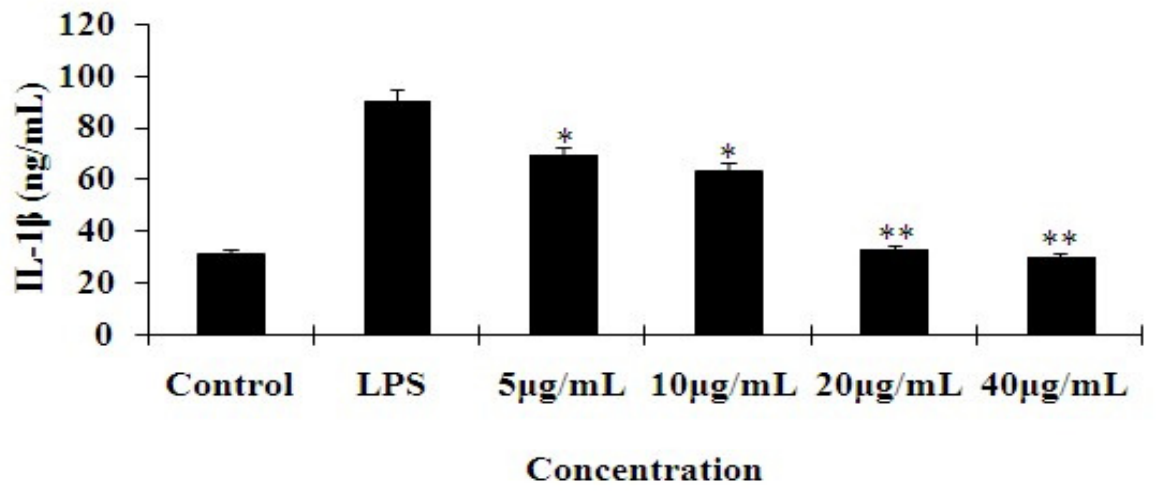

(c) 
Figure 4. Effects of 7-O-methylnaringenin (7-O-m) on MAPK in LPS-stimulated RAW 264.7 cells. The cells were pretreated with different concentrations $(10,20,40 \mu \mathrm{g} / \mathrm{mL})$ of 7-O-methylnaringenin for $1 \mathrm{~h}$ and then incubated with or without $1 \mu \mathrm{g} / \mathrm{mL}$ of LPS for 30 min. Protein samples were analyzed by Western blot with phospho-specific antibodies as described in materials and methods. The data are representative of three independent experiments and expressed as mean \pm SEM. ${ }^{* *} P<0.01 v s$. LPS group. ${ }^{\# \#} P<0.001 v s$. control group.
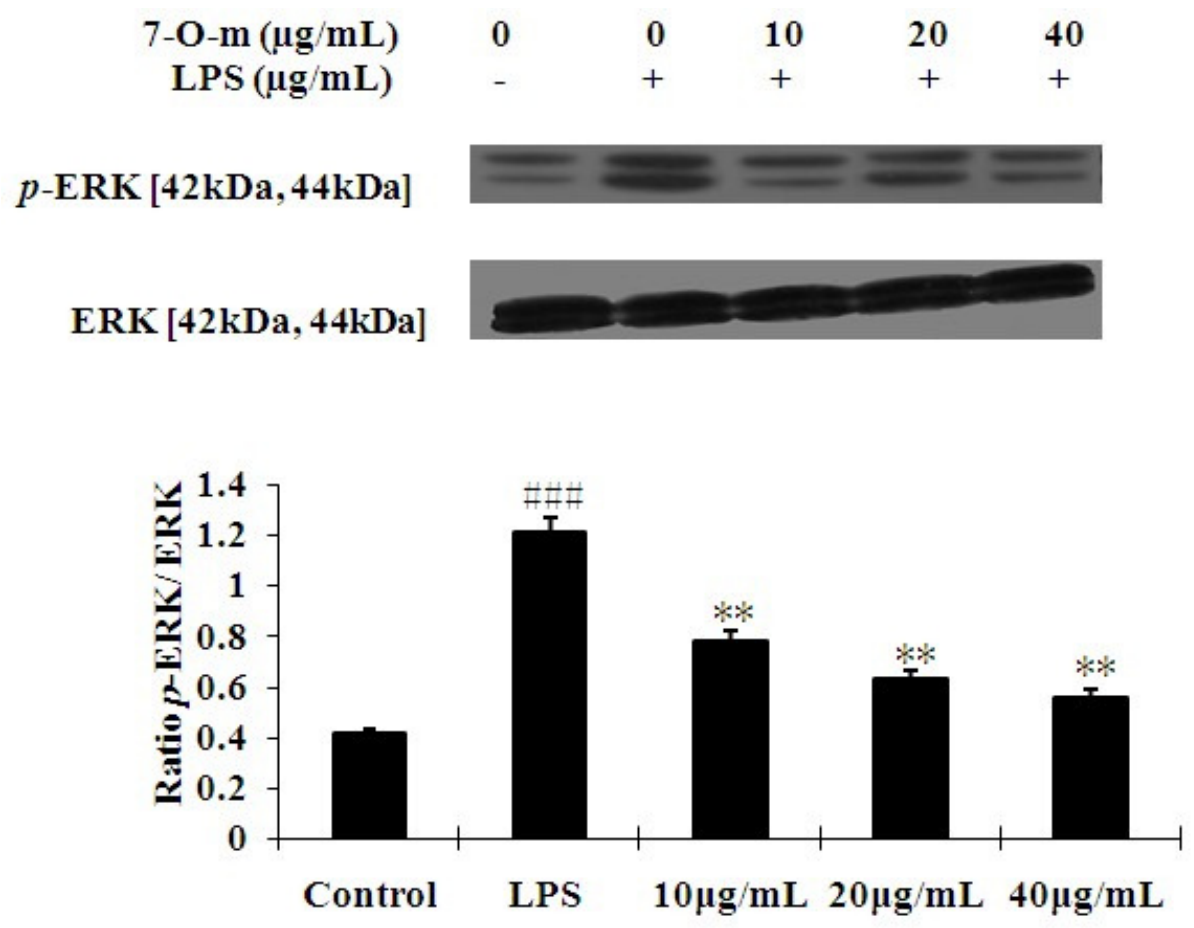

\section{Concentration}
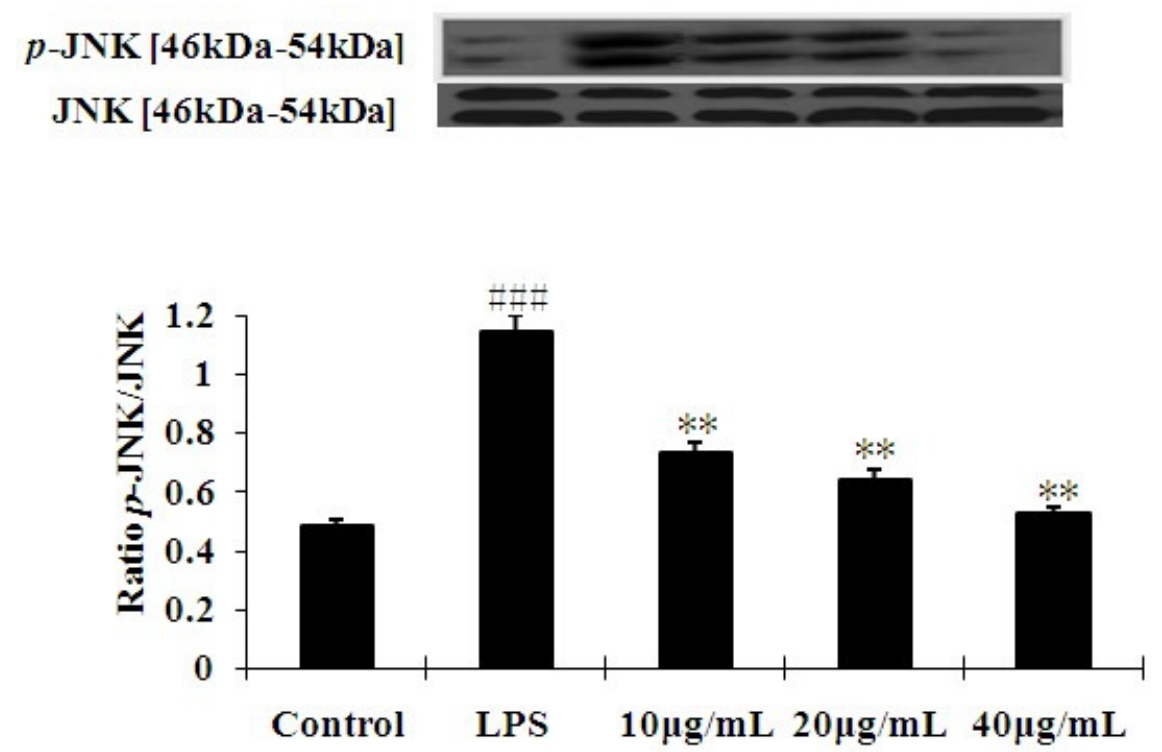

Concentration 
Figure 4. Cont.
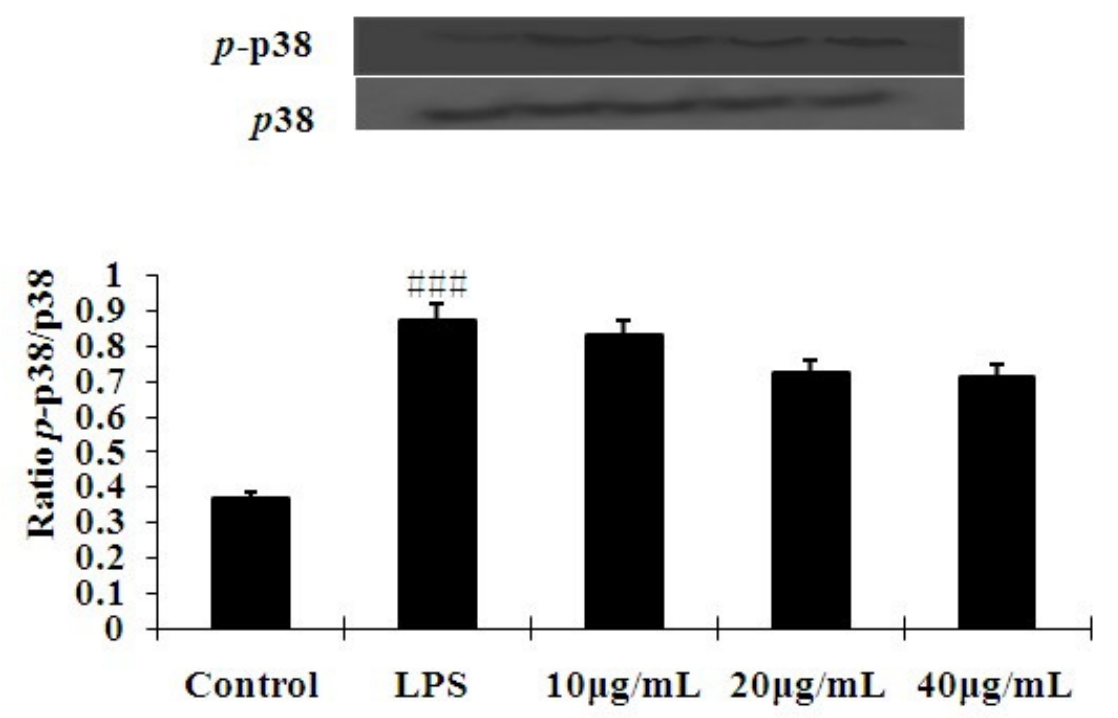

Concentration

\subsection{The Effect of 7-O-Methylnaringenin on LPS-Induced Degradation and Phosphorylation of IKB $\alpha$}

The NF- $\kappa \mathrm{B}$ transcription factor is preceded by the degradation and phosphorylation of I $\mathrm{B} \alpha$. Thus, we examined the effect of 7-O-methylnaringenin on $\mathrm{I} \kappa \mathrm{B} \alpha$ phosphorylation and degradation. Figure 5 shows that LPS-induced I $\mathrm{BB} \alpha$ degradation was significantly blocked by pre-treatment with 7-O-methylnaringenin. To determine whether this $\mathrm{I} \kappa \mathrm{B} \alpha$ degradation was related to I $\mathrm{B} \alpha$ phosphorylation, we examined the effect of 7-O-methylnaringenin on LPS-induced p-IкB $\alpha$. Western blot analysis showed that 7-O-methylnaringenin inhibited LPS-mediated $\mathrm{I} \kappa \mathrm{B} \alpha$ phosphorylation in a dose-dependent manner.

Figure 5. Effect of 7-O-methylnaringenin treatment on $\mathrm{I} \kappa \mathrm{B} \alpha$ phosphorylation and degradation. RAW 264.7 macrophage cells were pretreated with the concentrations $(10,20$, $40 \mu \mathrm{g} / \mathrm{mL}$ ) of $7-O$-methylnaringenin for $1 \mathrm{~h}$ and then the cells were incubated with LPS $(1 \mathrm{mg} / \mathrm{L})$ for $30 \mathrm{~min}$. Total cellular proteins were analyzed by western blot with specific antibodies. Quantification of protein expression was normalized to $\beta$-actin using a densitometer (Imaging System). The data are representative of three independent experiments and expressed as mean \pm SEM. $* * P<0.01$ vs. LPS group. ${ }^{\# \#} P<0.001$ vs. control group.

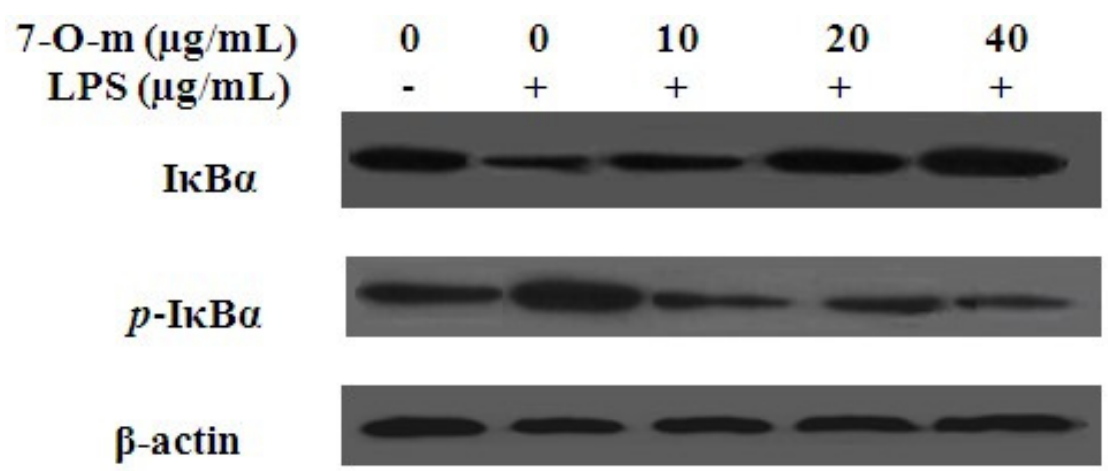


Figure 5. Cont.

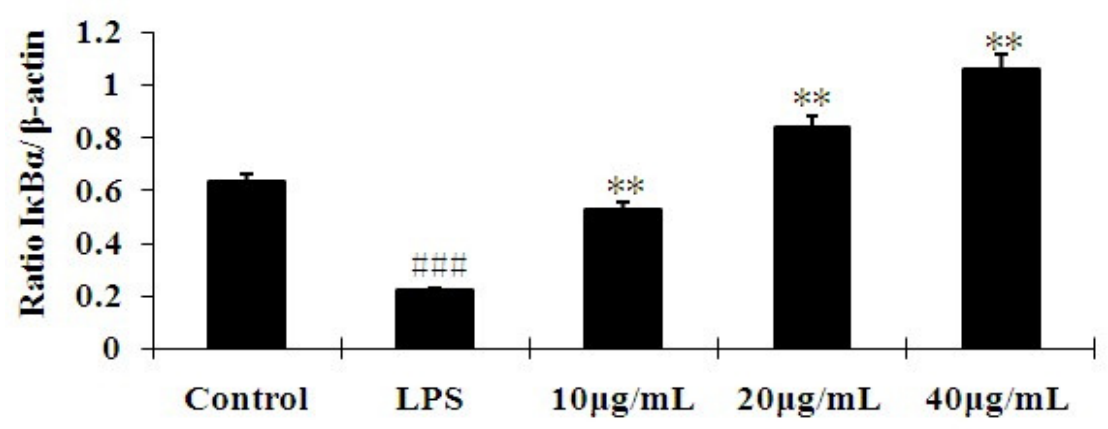

Concentration

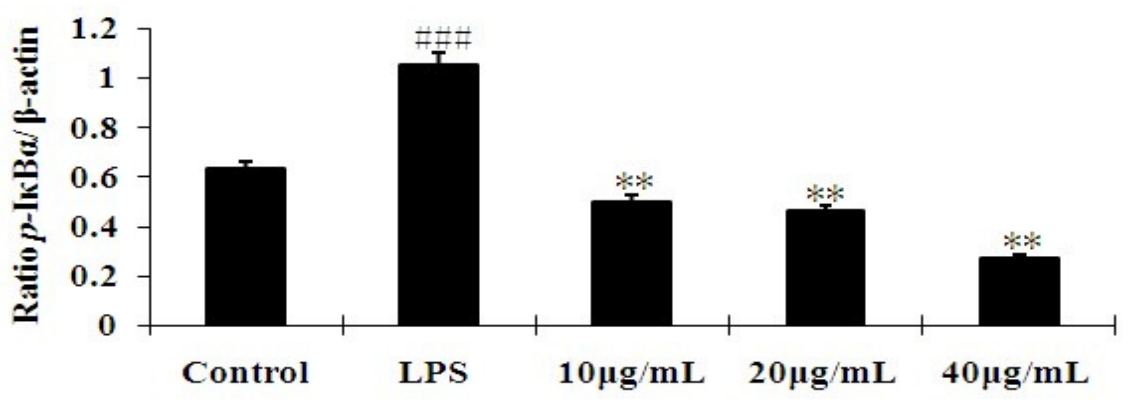

Concentration

\subsection{Discussion}

It is well known that pro-inflammatory cytokines induced by LPS, such as TNF- $\alpha$, IL-6 and IL-1 $\beta$, play a key role in the process of inflammatory diseases. Excessive production of these pro-inflammatory cytokines will result in a systemic inflammatory response syndrome, such as septic shock. Based on this information, the pharmacological inhibition of these inflammatory mediators is an important target in the treatment of endotoxemia with bacterial infection. In this paper, our data revealed that 7- $O$-methylnaringenin inhibited TNF- $\alpha$, IL-6 and IL- $1 \beta$ production in a dose-dependent manner in LPS-stimulated RAW 264.7 cells. It should be noted that this inhibitory effect was not due to cytotoxic activity of 7-O-methylnaringenin, because the cell viability was not affected by 7-O-methylnaringenin treatment.

We also investigated the mechanisms of action underlying such a function. Both MAPKs and $\mathrm{NF}-\kappa \mathrm{B}$ signaling pathways are involved in the LPS-induced pro-inflammatory mediators and cytokines expression, which play a critical role in the regulation of cell growth and differentiation as well as the control of cellular responses to cytokines and stresses [22,23]. Maximal MAPK expression is known to occur 20-30 min after LPS treatment in human and murine monocytes and macrophages [24]. Inhibition of any of the three MAPK pathways (JNK, p38 MAPK, and ERK) is sufficient to block induction of TNF- $\alpha$ by LPS [25-27]. Our results revealed that 7-O-methylnaringenin obviously down-regulated LPS-induced phosphorylation of ERK1/2 and JNK pathways in a dose-dependent manner, but the phosphorylation of p38 was not affected by 7-O-methylnaringenin treatment in activated macrophage cells (Figure 4). This result suggests that p38 is not involved in the inhibition by 7-O-methylnaringenin in RAW 264.7 cells. 
Nuclear factor- $\kappa \mathrm{B}$ participates in regulating the expression of cytokines and other mediators that are involved in the inflammatory response [28]. Thus, inhibition of the production of these signaling pathways may explain the potent activity of 7-O-Methylnaringenin as a suppressor of inflammatory cytokines. In unstimulated condition, NF- $\kappa \mathrm{B}$ is located in the cytoplasm as an inactive NF- $\kappa \mathrm{B} / \mathrm{I} \kappa \mathrm{B} \alpha$ complex and its activity is tightly controlled by the inhibitory protein $\mathrm{I} \kappa \mathrm{B} \alpha$. The phosphorylation-induced degradation of the $\mathrm{I} \kappa \mathrm{B} \alpha$ released the NF- $\kappa \mathrm{B}$ to enter the nucleus and activate specific target gene expression [29]. Therefore, the activation of NF- $\kappa B$ could be assessed in RAW cells by measuring the degree of phosphorylation of $\mathrm{I} \kappa \mathrm{B} \alpha$ protein. Incubation of macrophages with LPS caused markedly phosphorylation of cytosolic I $\kappa \mathrm{B} \alpha$, but 7-O-methylnaringenin significantly inhibited the phosphorylation of $\mathrm{I} \kappa \mathrm{B} \alpha$ (Figure 5). This means that 7-O-methylnaringenin could suppress the activation of the NF- $\mathrm{BB}$ signaling pathway.

\section{Experimental}

\subsection{Materials}

7-O-Methylnaringenin (purity $>98 \%$ ) was extracted from Rhododendron speciferum as described below. Dimethyl sulfoxide (DMSO), LPS (Escherichia coli 055:B5), and 3-(4,5-dimethylthiazol-2y1)-2,5-diphenyltetrazolium bromide (MTT) were purchased from Sigma Chemical Co. (St. Louis, MO, USA). Dulbecco's modified Eagle's medium (DMEM), fetal bovine serum (FBS), penicillin and streptomycin for cell culture were obtained from Invitrogen-Gibco (Grand Island, NY, USA). Mouse TNF- $\alpha$, IL-6 and IL-1 $\beta$ enzyme-linked immunosorbent assay (ELISA) kits were purchased from BioLegend Inc. (San Diego, CA, USA). The rabbit polyclonal anti-p54 JNK, rabbit polyclonal anti-ERK, rabbit polyclonal anti-p38, mouse monoclonal phospho-specific p46-p54 JNK antibodies, mouse monoclonal anti-phospho-ERK antibodies and mouse monoclonal phospho-specific p38 antibodies were purchased from Santa Cruz Biotechnology (Santa Cruz, CA, USA). Mouse mAb Phospho-I $\mathrm{B} \alpha$ and rabbit $\mathrm{mAb} \mathrm{I} \kappa \mathrm{B} \alpha$ were purchased from Cell Signaling Technology Inc (Beverly, MA, USA). Peroxidase-conjugated Affinipure goat anti-mouse $\operatorname{IgG}(\mathrm{H}+\mathrm{L})$ and peroxidase-conjugated Affinipure goat antirabbit IgG $(\mathrm{H}+\mathrm{L})$ were purchased from PTG (Chicago, IL, USA).

\subsection{Preparation of Extract}

The air-dried, powdered roots of Rhododendron speciferum $(9 \mathrm{~kg})$ (collected in Kunming, Yunnan Province, China, in October 2006) were extracted with $75 \% \mathrm{Me}_{2} \mathrm{CO} / \mathrm{H}_{2} \mathrm{O}(3 \times 25 \mathrm{~L}, 24 \mathrm{~h}$ each $)$ at room temperature. The filtrate was concentrated in vacuo to give a crude extract, which was then partitioned between $\mathrm{H}_{2} \mathrm{O}$ and EtOAc. The EtOAc portion $(250 \mathrm{~g})$ was divided into five fractions (Fractions A-E) over silica gel column $\left(\mathrm{CHCl}_{3}-\mathrm{MeOH}\right.$ 20:0, 19:1, 9:1, 8:2, 0:20). Fr. B (16 g, $\mathrm{CHCl}_{3^{-}}$ $\mathrm{MeOH}$ 19:1) was then chromatographed on silica gel $\left(\mathrm{CHCl}_{3}-\mathrm{Me}_{2} \mathrm{CO}\right.$ 9:1, 8:2, 7:3, 6:4) to afford four subfractions. 7-O-Methylnaringenin $(20 \mathrm{mg})$ was obtained from subfraction $\mathrm{B} 1\left(\mathrm{CHCl}_{3}-\mathrm{Me}_{2} \mathrm{CO} 9: 1\right.$, $2.3 \mathrm{~g})$ by Sephadex $\mathrm{LH}-20\left(\mathrm{CHCl}_{3}-\mathrm{MeOH} 1: 1\right)$. The compound's structural identity was determined by one-and two-dimensional nuclear magnetic resonance (NMR) spectroscopic analysis and comparison to published values. 


\subsection{Cell Culture and LPS Stimulation}

The RAW 264.7 mouse macrophage cell line was obtained from the China Cell Line Bank (Beijing, China). The cells were cultured in DMEM supplemented with $10 \%$ heat-inactivated FBS, $3 \mathrm{mM}$ Glutamine, antibiotics (100 U/mL penicillin and $100 \mathrm{U} / \mathrm{mL}$ streptomycin) at $37{ }^{\circ} \mathrm{C}$ under a humidified atmosphere of $5 \% \mathrm{CO}_{2}$. In all experiments, cells were allowed to acclimate for $24 \mathrm{~h}$ before any treatments. Cells were incubated with or without 7-O-methylnaringenin that was always added $1 \mathrm{~h}$ prior to LPS treatment.

\subsection{MTT Assay for Testing Cell Viability}

Cytotoxicity studies induced by 7- $O$-methylnaringenin were performed by the MTT assay. RAW 264.7 cells were mechanically scraped, plated at a density of $4 \times 10^{5}$ cells $/ \mathrm{mL}$ onto 96 -well plates containing $100 \mu \mathrm{L}$ of DMEM medium, and incubated in a $37{ }^{\circ} \mathrm{C}, 5 \% \mathrm{CO}_{2}$ incubator overnight. 7-O-methylnaringenin was dissolved in DMSO, and the DMSO concentrations in all assays did not exceed $0.1 \%$. After overnight incubation, the cells were treated with diverse concentrations of 7-O-methylnaringenin $(0-50 \mu \mathrm{g} / \mathrm{mL})$ in the presence or absence of LPS $(1 \mu \mathrm{g} / \mathrm{mL})$ according to the experimental design. After $18 \mathrm{~h}, 20 \mu \mathrm{L}$ of $5 \mathrm{mg} / \mathrm{mL}$ MTT was added to each well and the cells were further incubated for an additional $4 \mathrm{~h}$. MTT was removed and cells were lysed with $150 \mu \mathrm{L} /$ well DMSO. The optical density was measured at $570 \mathrm{~nm}$ on a microplate reader (Tecan, Groedig, Austria).

\subsection{Measurement of Cytokine Production}

To investigate the effect of 7-O-methylnaringenin on cytokine levels from LPS-treated cells, RAW 264.7 cells $\left(4 \times 10^{5}\right.$ cells $\left./ \mathrm{mL}\right)$ seeded into 24 -well plates were pretreated with $5,10,20,40 \mu \mathrm{g} / \mathrm{mL}$ of 7-O-methylnaringenin for $1 \mathrm{~h}$ prior to $24 \mathrm{~h}$ treatment with $1 \mathrm{mg} / \mathrm{L} \mathrm{LPS}$ in a $37^{\circ} \mathrm{C}, 5 \% \mathrm{CO}_{2}$ incubator. Cell-free supernatants were collected and stored at $-20{ }^{\circ} \mathrm{C}$ until assayed for cytokine levels. The concentrations of TNF- $\alpha$, IL- 6 and IL-1 $\beta$ in the supernatants of RAW 264.7 cell cultures were determined using an ELISA kit, according to the manufacturer's instructions (BioLegend, Inc.).

\subsection{Western Blot Analysis}

RAW 264.7 cells $\left(4 \times 10^{5}\right.$ cells $\left./ \mathrm{mL}\right)$ were plated onto 6 -well plates and pretreated with 10,20 , $40 \mu \mathrm{g} / \mathrm{mL}$ of $7-O$-methylnaringenin for $1 \mathrm{~h}$ and then stimulated with $1 \mu \mathrm{g} / \mathrm{mL}$ of LPS for $30 \mathrm{~min}$. The cells were collected by centrifugation and washed twice with ice-cold PBS. The washed cell pellets were resuspended in extraction lysis buffer [50 mM Tris ( $\mathrm{pH} 7.6$ ), $150 \mathrm{mM} \mathrm{NaCl}, 5 \mathrm{mM}$ EDTA (pH 8.0), 0.6\% NP-40, $1 \mathrm{mM} \mathrm{Na} \mathrm{VO}_{4}, 20 \mathrm{mM} \beta$-glycerophosphate, $1 \mathrm{mM}$ phenylmethylsulfonyl fluoride, $2 \mathrm{mM}$ p-nitrophenyl phosphate and 1:25 Complete Mini Protease Inhibitor cocktail (Boehringer, Mannheim, Germany)]. After the lysates were incubated on ice for $30 \mathrm{~min}$, they were centrifuged $\left(12,000 \mathrm{~g}\right.$ at $\left.4{ }^{\circ} \mathrm{C}\right)$ for $5 \mathrm{~min}$ to obtain the cytosolic fraction. The protein concentration was determined using the Bradford assay (Bio-Rad, Munich, Germany) according to the manufacturer's instructions. The samples of cellular protein from treated and untreated cell extracts were separated by sodium dodecyl sulphate (SDS)-polyacrylamide gel electrophoresis (PAGE) and then electroblotted onto a polyvinylidene difluoride (PVDF) membrane. The immunoblot was incubated overnight with 
blocking solution (5\% (wt/vol) nonfat dry milk), followed by incubation for $4 \mathrm{~h}$ with monoclonal phospho-specific antibodies to I $\mathrm{B} \alpha$, p46-p54 JNK, p42/p44 ERK, and p38mapk in 5\% (wt/vol) bovine serum albumin (BSA) dissolved in TTBS. Blots were washed with Tween 20/Tris-buffered saline [TTBS, $20 \mathrm{mM}$ Tris- $\mathrm{HCl}$ buffer, $\mathrm{pH}$ 7.6, containing $137 \mathrm{mM} \mathrm{NaCl}$ and $0.05 \%$ (vol/vol) Tween 20] and incubated with a peroxidase-conjugated secondary anti-mouse antibody. Blots were again washed with TTBS and the bound antibodies were detected using ECL plus (GE Healthcare, Buckinghamshire, UK).

\subsection{Statistical Analysis}

Data values were expressed means \pm SEM. Data were analyzed by analysis of variance (ANOVA) and two-tailed Student's t-test. Statistical difference was accepted at $p<0.05$.

\section{Conclusions}

In summary, the anti-inflammatory effects of 7-O-methylnaringenin in LPS-activated macrophages are due to down-regulation the secretion of TNF- $\alpha$, IL-6 and IL-1 $\beta$. The related mechanism is by preventing activation of NF-қB, ERK1/2 and JNK/MAPKs signalling pathways.

\section{Acknowledgments}

The authors thank the National Nature Science Foundation of China (No. 3097221) and Chinese postdoctoral station of Jilin University (No. 20090461034) for their great support in financing this research.

\section{References and Notes}

1. Feghali, C.A.; Wright, T.M. Cytokines in acute and chronic inflammation. Front. Biosci. 1997, 2, 12-26.

2. Shimazu, R.; Akashi, S.; Ogata, H.; Nagai, Y.; Fukudome, K.; Miyake, K. MD-2, a molecule that confers lipopolysaccharide responsiveness on Toll-like receptor 4. J. Exp. Med. 1999, 189, 1777-1782.

3. Beutler, B.; Krochin, N.; Milsark, I.W.; Luedke, C.; Cerami, A. Control of cachechin (tumor necrosis factor) synthesis: Mechanisms of endotoxin resistance. Science 1986, 232, 977-980.

4. Morrison, D.C.; Danner, R.L.; Dinarello, C.A.; Munford, R.S.; Natanson, C.; Pollack, M.; Spitzer, J.J.; Ulevitch, R.J.; Vogel, S.N.; McSweegan, E. Bacterial endotoxins and pathogenesis of Gram-negative infections: Current status and future direction. J. Endotoxin Res. 1994, 1, 71-83.

5. Levine, B.; Kalman, J.; Mayer, L.; Fillit, H.M.; Packer, M. Elevated circulating levels of tumor necrosis factor in severe chronic heart failure. N. Engl. J. Med. 1990, 323, 236-241.

6. Bartold, P.M.; Haynes, D.R. Interleukin-6 production by human gingival fibroblasts. J. Periodontal Res. 1991, 26, 339-345.

7. van Meir, E.; Sawamura, Y.; Diserens, A.C.; Hamou, M.F.; de Tribolet, N. Human glioblastoma cells release interleukin 6 in vivo and in vitro. Cancer Res. 1990, 50, 6683-6688.

8. Lu, X.Y.; Wang, Z.C.; Yang, G.Z. The relationships between IL-1, IL-6 and tumor. Guowai Yixue Shengli Bingli Kexue Yu Linchuang Fence 1995, 15, 159-163. 
9. Kielian, T.; Bearden, E.D.; Baldwin, A.C.; Esen, N. IL-1 and TNF-alpha play a pivotal role in the host immune response in a mouse model of Staphylococcus aureus-induced experimental brain abscess. J. Neuropathol. Exp. Neurol. 2004, 63, 381-396.

10. Morrissey, P.J.; Charrier, K. Treatment of mice with IL-1 before infection increases resistance to a lethal challenge with Salmonella typhimurium. The effect correlates with the resistance allele at the Ity locus. J. Immunol. 1994, 153, 212-219.

11. Yao, L.H.; Jiang, Y.M.; Shi, J.; Tomas-Barberan, F.A.; Datta, N.; Singanusong, R. Flavonoids in food and their health benefits. Plant Foods Hum. Nutr. 2004, 59, 113-122.

12. Boots, A.W.; Haenen, G.R.; Bast, A. Health effects of quercetin: From antioxidant to nutraceutical. Eur. J. Pharmacol. 2008, 585, 325-337.

13. Gomes, A.; Fernandes, E.; Lima, J.L.; Mira, L.; Corvo, M.L. Molecular mechanisms of anti-inflammatory activity mediated by flavonoids. Curr. Med. Chem. 2008, 15, 1586-1605.

14. Kawai, M.; Hirano, T.; Higa, S.; Arimitsu, J.; Maruta, M.; Kuwahara, Y. Flavonoids and related compounds as anti-allergic substances. Allergol. Int. 2007, 56, 113-123.

15. Cushnie, T.P.; Lamb, A.J. Antimicrobial activity of flavonoids. Int. J. Antimicrob. Agents 2005, 26, 343-356.

16. Hirpara, K.V.; Aggarwal, P.; Mukherjee, A.J.; Joshi, N.; Burman, A.C. Quercetin and its derivatives: Synthesis, pharmacological uses with special emphasis on anti-tumor properties and prodrug with enhanced bio-availability. Anticancer Agents Med. Chem. 2009, 9, 138-161.

17. Aalinkeel, R.; Bindukumar, B.; Reynolds, J.L.; Sykes, D.E.; Mahajan, S.D.; Chadha, K.C. The dietary bioflavonoid, quercetin, selectively induces apoptosis of prostate cancer cells by down-regulating the expression of heat shock protein 90. Prostate 2008, 68, 1773-1789.

18. Tan, J.; Wang, B.; Zhu, L. Regulation of survivin and Bcl-2 in HepG2 cell apoptosis induced by quercetin. Chem. Biodivers. 2009, 6, 1101-1110.

19. Perez-Vizcaino, F.; Duarte, J.; Jimenez, R.; Santos-Buelga, C.; Osuna, A. Antihypertensive effects of the flavonoid quercetin. Pharmacol. Rep. 2009, 61, 67-75.

20. Saito, T.; Abe, D.; Sekiya, K. Sakuranetin induces adipogenesis of 3T3-L1cells through enhanced expression of PPARgamma2. Biochem. Biophys. Res. Commun. 2008, 372, 835-839.

21. Ahmed, M.S.; Galal, A.M.; Ross, S.A.; Ferreira, D.; ElSohly, M.A.; Ibrahim, A.S.; Mossa, J.S.; El-Feraly, F.S. A weakly antimalarial biflavanone from Rhus retinorrhoea. Phytochemistry 2001, $58,599-602$.

22. Johnson, G.L.; Lapadat, R. Mitogen-activated protein kinase pathways mediated by ERK, JNK, and p38 protein kinases. Science 2002, 298, 1911-1912.

23. Caivano, M. Role of MAP kinase cascades in inducing arginine transporters and nitric oxide synthetase in RAW 264 macrophages. FEBS Lett. 1998, 429, 249-253.

24. Bian, Z.M.; Elner, S.G.; Yoshida, A.; Elner, V.M. Human RPE-monocyte co-culture induces chemokine gene expression through activation of MAPK and NIK cascade. Exp. Eye Res. 2003, 76, 573-583.

25. Kontoyiannis, D.; Pasparakis, M.; Pizarro, T.T.; Cominelli, F.; Kollias, G. Impaired on/off regulation of TNF biosynthesis in mice lacking TNF AU-rich elements: Implications for joint and gut-associated immunopathologies. Immunity 1999, 10, 387-398. 
26. Kotlyarov, A.; Neininger, A.; Schubert, C.; Eckert, R.; Birchmeier, C.; Volk, H.D.; Gaestel, M. MAPKAP kinase 2 is essential for LPS-induced TNF-alpha biosynthesis. Nat. Cell Biol. 1999, 1, 94-97.

27. Dumitru, C.D.; Ceci, J.D.; Tsatsanis, C.; Kontoyiannis, D.; Stamatakis, K.; Lin, J.H.; Patriotis, C.; Jenkins, N.A.; Copeland, N.G.; Kollias, G.; et al. TNF- $\alpha$ induction by LPS is regulated posttranscriptionally via a Tpl2/ERK-dependent pathway. Cell 2000, 103, 1071-1083.

28. Baeuerle, P.A.; Baltimore, D. NF-kappa B: Ten years after. Cell 1996, 87, 13-20.

29. Phan, H.H.; Cho, K.; Sainz-Lyon, K.S.; Shin, S.; Greenhalgh, D.G. CD14-dependent modulation of NF-кB alternative splicing in lung after burn injury. Gene 2006, 371, 121-129.

Sample Availability: Samples of 7-O-methylnaringenin are available from the authors.

(C) 2012 by the authors; licensee MDPI, Basel, Switzerland. This article is an open access article distributed under the terms and conditions of the Creative Commons Attribution license (http://creativecommons.org/licenses/by/3.0/). 